\title{
Research on the control method of test platform of marine component mechanical properties
}

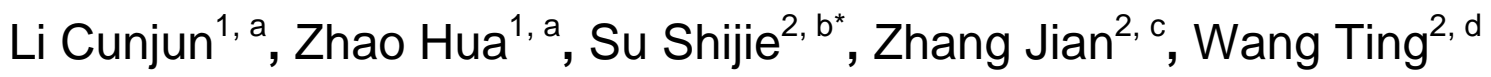

${ }^{1}$ Zhoushan Institute of Calibration and Testing for Quality and Technology Supervision, Zhoushan Zhejiang 316000, China; ${ }^{2}$ School of Mechanical Engineering, Jiangsu University of Science and Technology, Zhenjiang Jiangsu 212003, China

azzzjzx@163.com, bdecand@163.com, czhjian127@163.com, d867906938@qq.com

Keywords: Large marine components; Control systems; Electro-hydraulic servo system.

Abstract :According to characteristics of high flow, high inertia load, variable stiffness of test platform in marine component mechanical properties, considering the president research status of hydraulic servo system, this paper establish the mathematical model of hydraulic servo system of test platform and give a analysis to load performance of test platform, and come up with a method that using flow servo valve and proportional relief valve combination control to realize loading force controlled by close loop. This method can realize loading force under controlling and improve the precision of control system.

\section{Introduction}

Large test platform of marine component mechanical properties as a large multi-function testing machine can realize the tensile and compressive tests on marine components. To the test platform's control system, since the platform's multi-function and the objects to be measured are diverse, loading force is also changed accordingly.For the control of loading force, we usually achieve it by means of a feedback loop ${ }^{[1-2]}$. This control method mostly implements precise control through pressure servo valve with feedback loops. But the feedback loop is so small that it is not ideal when they connect with other components signal and the control accuracy will be affected. Another feedback control strategy is to use flow servo valve with large feedback loop to achieve precise control, this control method is also widely used in practical applications.But this strategy requires higher initial pressure which leading to the system power consumption is very large ${ }^{[3]}$.

The object of this paper is $12 \mathrm{MN}$ test platform of marine component mechanical properties which feature is that the objects under testing are multitudinous (including chain, wire rope, anchors, derricks, etc) and the stiffness vary widely. Through a variety of control methods in-depth studying, a method to improve the performance of the system is presented. In terms of loading force control in controlling system of test platform, we adopt the flow servo valve and proportional relief valve combination control to achieve regulatory function by flow servo valve and working pressure controlling by proportional overflow valve. The former combines with the later to realize the control of loading force.

\section{Mathematical model of the control system of test platform}

The control system of test platform of marine component mechanical properties is with IPC as the core control system ${ }^{[4]}$. The system belongs to the electro-hydraulic servo control system for multifunctional mechanics test and mainly comprising of the IPC, proportional relief valve, flow servo valve, hydraulic cylinders, data acquisition cards and displacement sensors.

Based on the operating characteristics of servo valve, the linear flow equations are:

$$
q_{L}=K_{Q} x_{v}-K_{C} p_{L}
$$

In this formula: $\mathrm{q}_{L}$ - Hydraulic loading flow; $\mathrm{p}_{L}$ - Imposed load; $X_{V}$ - Piston spool displacement; $K_{Q}$ - Proportional servo valve flow gain; $K_{C}$ - Proportional servo valve flow coefficient; 
By the flow continuation theorem known as the hydraulic cylinders flow continuity equation is:

$$
q_{L}=A \frac{d x_{p}}{d t^{2}}+c_{t c} p_{L}+\frac{V_{t}}{4 \beta_{e}} \bullet \frac{d p_{L}}{d t}
$$

In this formula: $\mathrm{A}$ - Piston oil Chamber cross-sectional area; $\mathrm{X}_{P}$-Piston displacement; $C_{t c}$ - Hydraulic cylinder leakage coefficient; $V_{\mathrm{t}}$ - Hydraulic cylinder and pipe volume and;

$\beta_{e}$ - Elastic modulus of hydraulic oil;

Balance equation about Imposed load and hydraulic cylinders is:

$$
p_{L}=\frac{1}{A}\left(m_{t} \frac{d^{2} x_{p}}{d t^{2}}+B_{c} \frac{d x_{p}}{d t}+K_{p} x_{p}+F\right)
$$

In this formula: $\mathrm{m}_{t}$ - Total quality system parts; $B_{C}$ - Viscous damping coefficient; $K_{\mathrm{p}}$ - Elastic stiffness under test; $\quad F$ - External disturbance forces.

From (1), (2), (3) mentioned above formulas we get control system block diagram in Figure1.

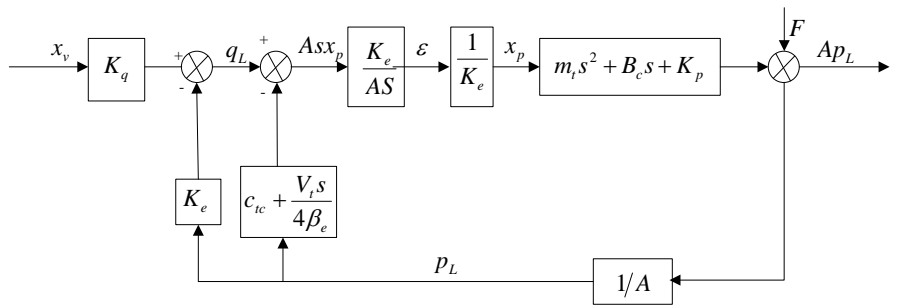

Fig. 1. The control system's block diagram

\section{Performance analysis of the testing platform's control system}

The main parameter of $12 \mathrm{MN}$ control system of testing platform of marine component mechanical properties are loading force and experiment displacement.In the process of testing, the control mode of testing platform's control system includs the control of loading force test and displacement test. Focusing on the complexity of testing platform for loading, we are now analyzing the loading characteristics of the elastic load that the most commonly used in the testing platform.

From the Figure 1 when considering elastic load, the displacement of the piston rod $X_{p}$ and main control signal $\mathrm{X}_{\mathrm{v}}$ transfer function are as follows:

$$
\frac{x_{p}}{x_{v}}=\frac{\frac{K_{q} A}{K_{p} K_{c e}}}{\left(\frac{s}{\omega_{3}}+1\right)\left(\frac{s^{2}}{\omega_{1}^{2}}+\frac{2 \xi_{1}}{\omega_{1}} s+1\right)}
$$

The transfer function of loading force $\mathrm{F}_{\mathrm{L}}$ and main control signal $\mathrm{X}_{\mathrm{V}}$ is:

$$
\frac{F_{L}}{x_{v}}=\frac{\frac{K_{q} A}{K_{c e}}\left(\frac{s^{2}}{\omega_{1}^{2}}+\frac{2 \xi_{1}}{\omega_{1}} s+1\right)}{\left(\frac{s}{\omega_{3}}+1\right)\left(\frac{s^{2}}{\omega_{1}^{2}}+\frac{2 \xi_{1}}{\omega_{1}} s+1\right)}
$$

From the upper formulas we can obtain the block diagram of displacement control considering the elastic load in Figure 2 as follows.

As can be known from the Figure 2 shows that the displacement control considering the elastic load for the open-loop transfer function of the form as follows:

$$
G(s) H(s)=\frac{\frac{K_{a} K_{g v} K_{H 1} K_{q} A}{K_{p} K_{c e}}}{\left(\frac{s}{\omega_{3}}+1\right)\left(\frac{s^{2}}{\omega_{1}^{2}}+\frac{2 \zeta_{1}}{\omega_{1}} s+1\right)}
$$

In the upper formula: $K_{a}$ - Electrical amplification factor; $K_{\mathrm{gv}}$ - Servo valve gain; $K_{\mathrm{q}}$ - Hydraulic valve flow gain; $A$ - Cylinder area; $K_{\mathrm{H} 1}$ - Feedback amplification factor; $K_{\mathrm{ce}}$ - flow coefficient about leakage of total pressure. 
By the equation (6), the Bode diagram of control system of testing platform can be obtained under flexible load when displacement is being controlled in Figure 3 as follows.

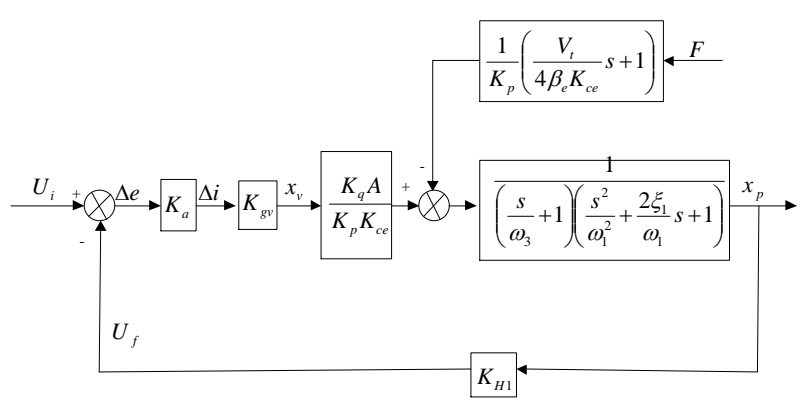

Fig.2.The block diagram of testing platform's displacement control considering elastic load

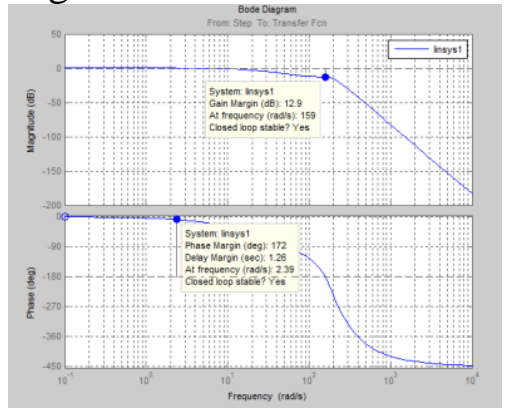

Fig.3. The Bode diagram of elastic loading displacement control system

By the upper diagram we can directly get the system's phase margin is $172^{\circ}$ and gain margin is $12.9 \mathrm{~dB}$.The diagram shows that the system gain margin and phase margin are both positive. Then the system is stable and no need to be corrected.

The testing platform is in an elastic loading state when objects are loaded during the test and control system function diagram of the entire platform shown as in Figure 4.From the figure we can get the bode diagram of testing platform's loading force control considering elastic in Figure 5.

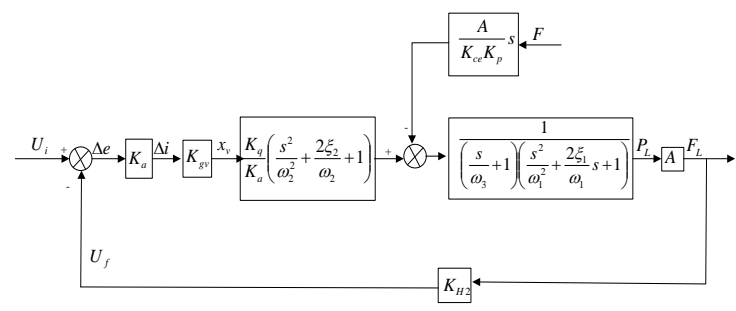

Fig.4.The block diagram of testing platform's loading force control considering elastic load

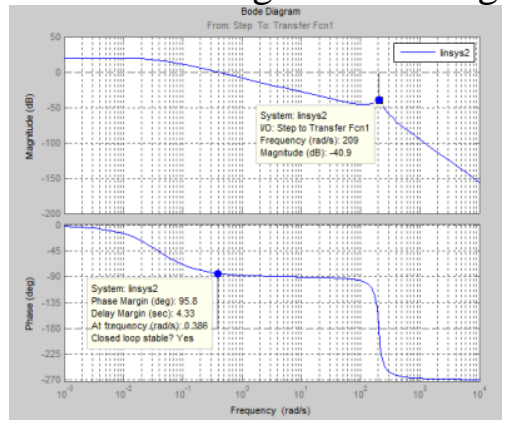

Fig.5 The Bode diagram of elastic loading force control system

By the upper diagram we can directly get the system's phase margin is $95.8^{\circ}$ and gain margin is $-40.9 \mathrm{~dB}$. The diagram shows that the gain margin of system is negative .So the system model is unstable and need to be calibrated.

Through the mathematical analysis of elastic loading force control system's performance shows that: the performance analysis of displacement control under elastic loading have a better stability than force control performance at the same load.

\section{Research on the control method of test platform}

Based on the analysis about $12 \mathrm{MN}$ test platform of marine component mechanical properties in elastic loading displacement control performance and force control performance, we adopt the method that the flow servo valve and proportional relief valve are combined with controlling and achieve regulatory function by flow servo valve and working pressure is controlled by proportional overflow valve. The theory shown as Figure 6.

1-Vane pump;2-Piston pump with constant pressure variable;

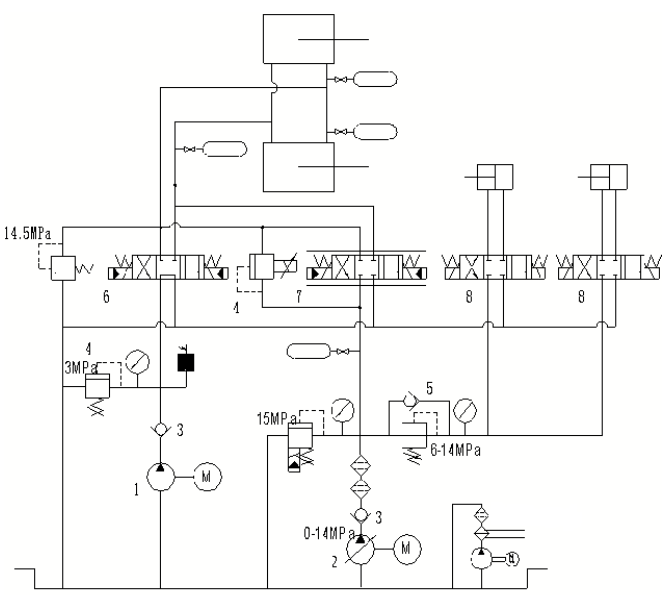

3-Way valve; 4-Proportional overflow valve;

5-Pilot operated pressure reducing valve;

6- Electro-hydraulic valve;7- Flow servo valve8- Solenoid valve

Fig.6.The theory diagram of test platform hydraulic system.

All testing machine are the typical static loading control system which the electro-hydraulic 
Proportional valve can be seen as a tandem control system consisting of a first step loop and a proportional loop. The transfer function for electro-hydraulic proportional valve is as follows:

$$
\frac{P(s)}{U(s)}=\frac{K_{i}}{\frac{s}{\omega_{s m}}+1}
$$

The flow equation of proportional overflow valve under ideal conditions is as follows:

$$
q_{v}=\frac{-K_{i} U+\left(\frac{s}{\omega_{s m}}+1\right) p_{L}}{\left(\frac{s}{\omega_{v}}+1\right) K_{0}}
$$

In the upper formula: $K_{i}$ - The pressure relief valve gain; $U$ - For a given input voltage; $\omega_{\mathrm{sm}}$ - Oscillation frequency of the relief valve; $\omega_{\mathrm{v}}$ - Corner frequency of the relief valve; $K_{\text {o }}$ - Relief valve oil resistance.

From the hydraulic cylinder flow equation (2) we can know the following formula:

$-q_{v}=A s x_{p}+c_{t c} p_{L}+\frac{V_{t}}{4 \beta_{e}} \bullet s p_{L}$

Under the ideal conditions hydraulic oil cylinder leaks are not taken into account, so the formula is founded $\left(c_{t c}=0\right)$. Then the formula (9) can be transferred into the following form:

$$
x_{p}=-\frac{1}{A s}\left(\frac{V_{t}}{4 \beta_{e}} s p_{L}+q_{v}\right)
$$

So we can get the following form:

$$
p_{L}=\frac{K_{i}\left(m_{t} s^{2}+B_{c} s+K_{p}\right) U}{a_{0} s^{4}+a_{1} s^{3}+a_{2} s^{2}+a_{3} s+a_{4}}
$$

In the upper formula: $a_{0}=\frac{K_{0} m_{t} V_{t} ;}{4 \beta_{e} \omega_{v}} ; \quad a_{1}=\frac{K_{0} V_{t} B_{c}}{4 \beta_{e} \omega_{v}}+\frac{K_{0} V_{t} m_{t}}{4 \beta_{e}}+\frac{m_{t}}{\omega_{s m}} ;$

$a_{2}=\frac{K_{0} V_{t} K_{p}}{4 \beta_{e} \omega_{v}}+\frac{K_{0} V_{t} B_{c}}{4 \beta_{e}}+\frac{B_{c}}{\omega_{s m}}+m_{t}+\frac{K_{0} A^{2} ;}{\omega_{v}} ; \quad a_{3}=\frac{K_{0} V_{t} K_{p}}{4 \beta_{e}}+B_{c}+\frac{K_{p}}{\omega_{s m}}+K_{0} A^{2} ; \quad a_{4}=K_{p}$.

The proportional overflow valve of testing platform's control system under the loading control function control block diagram is shown in Figure 7 below. From the Figure7 we can obtain the open-loop transfer function of proportional overflow valve in testing platform's control system under the loading control.

$$
G(s) H(s)=\frac{K_{i}\left(m_{t} s^{2}+B_{c} s+K_{p}\right) K_{f}}{a_{0} s^{4}+a_{1} s^{3}+a_{2} s^{2}+a_{3} s+a_{4}}
$$

By the equation (12), the Bode diagram of electro-hydraulic servo control system of testing platform can be obtained in the following Figure 8.

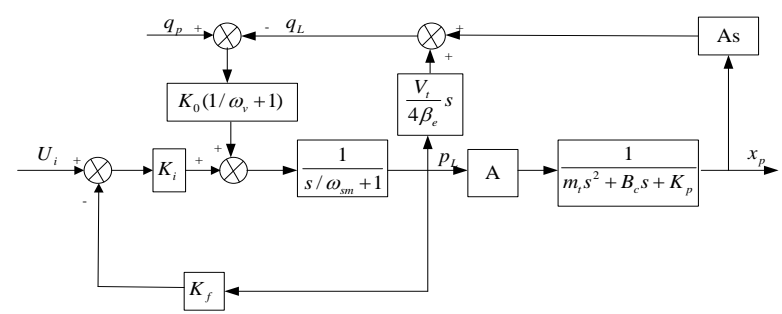

Fig.7.The block diagram of proportional overflow valve in testing platform's control system under the loading control

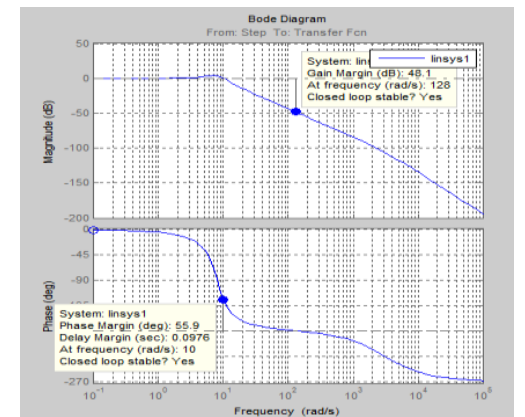

Fig.8. The Bode diagram of electro-hydraulic servo control system

From the upper simulation chart and data, we know that when the system is in using flow servo valve and proportional relief valve combination control, the phase margin of the system is $55.9^{\circ}$ and gain margin is $48.1 \mathrm{~dB}$. The diagram shows the system gain margin and phase margin are both posive. 
Then the system is stable and no need to be corrected, this method can realize loading force under controlling and achieve better system performance and stability.

\section{Application examples}

This section shows the emergency towing tests as an example. In the actual operation process, the practical application of control system is given.The physical picture of the testing platform after being completely installed shows in Figure 9.

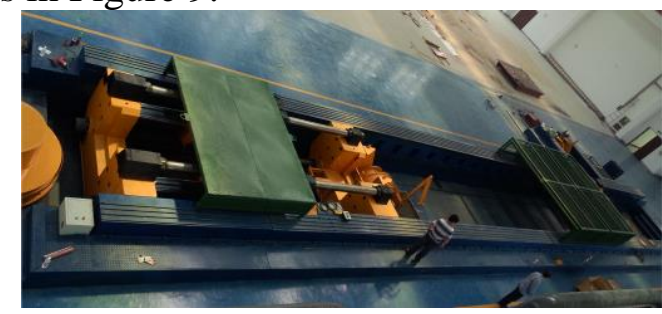

Fig.9.Emergency towing test site map

\section{Summary}

1. By reading the relevant domestic and foreign literature we understand the research status of control system in the field of testing machines. Based on the above, we carry out study on the control algorithm of $12 \mathrm{MN}$ multi-functional tensile testing machine's control system and have carried out the theoretical modeling on the test platform's control system using modern control theory.

2. Through the analysis of loading displacement and force control performance considering elastic load, we have established transfer functions and block diagrams corresponding. Bode diagram have been drawn on this basis and analyzed the stability of test platform's control system. Finally a method to improve the stability of the system load performance has been proposed.

3.According to the previous analysis, we adopt the flow servo valve and proportional relief valve combination control to achieve the loading stability of test platform's control system. The flow servo valve is realized regulatory function and the proportional relief valve is operated pressure controlling. The former combines with the later to realize the control of loading force. At last the control accuracy of double valve control system has been verified.

\section{Acknowledgements}

This work was financially supported by public welfare industry research foundation of General Administration of Quality Supervision, Inspection and Quarantine of the People's Republic of China (Grant No. 201310111).

\section{References}

[1] Clarke D W, Hinton C J. Adaptive control of materials-testing machines[J]. Automatica. 1997, 33(6): 1119-1131.

[2] S.R.Lee, K.Srinivation. Self-Tuning Control Applieation to Closedd-loop Servo-hydraulic Material Testing[J]. Dynamic Systems Measurement and Control, 2000(112): 431-437.

[3] Yao J, Jiao Z, Yao B, et al. Nonlinear Adaptive Robust Force Control of Hydraulic Load Simulator[J]. Chinese Journal of Aeronautics. 2012, 25(5): 766-775. (in Chinese)

[4] YAN Jun, LI Bo, GUO Gang. Nonlinear Modeling and Identification of the Electro-hydraulic Control System of an Excavator Arm Using BONL Model[J]. Chinese Journal of Mechanical Engineering, 2013, 06: 1212-1221. (in Chinese)

[5] Zhu Ben being. 3500KN development of the test system for static load testing platform [D]. Zhejiang University, 2014. (in Chinese) 